\title{
Prediction of weld quality using intelligent decision making tools
}

\author{
J. Edwin Raja Dhas ${ }^{1}$, Somasundaram Kumanan ${ }^{2}$, C.P. Jesuthanam ${ }^{3}$ \\ 1. Department of Automobile Engineering, Noorul Islam University, Tamil Nadu, India. 2. Department of Production \\ Engineering, National Institute of Technology. Tiruchirappalli, India. 3. Principal, Narayanaguru College of Engineering, \\ Nagercoil, India.
}

Correspondence: J. Edwin Raja Dhas. Address: Department of Automobile Engineering, Noorul Islam University, PO box 629161, Tamil Nadu, India. Telephone: 91-046-136-6297. E-mail: edwinrajadhas@rediffmail.com.

Received: March 26, 2012

Accepted: September 23, 2012

Published: December 1, 2012

DOI : 10.5430/air.v1n2p131

URL: http://dx.doi.org/10.5430/air.v1n2p131

\begin{abstract}
Decision-making process in manufacturing environment is increasingly difficult due to the rapid changes in design and demand of quality products. To make decision making process online, effective and efficient artificial intelligent tools like neural networks are being attempted. This paper proposes the development of neural network models for prediction of weld quality in Submerged Arc Welding (SAW). Experiments are designed according to Taguchi's principles and mathematical equations are developed using multiple regression model. Proposed neural network models are developed using experimental data, supported with the data generated by regression model. The performances of the developed models are compared in terms of computational speed and prediction accuracy. It is found that Neural Network trained with Particle Swarm Optimization (NNPSO) performs better than Neural Network trained with Back Propagation (BPNN) algorithm, Radial Basis Functional Neural Network (RBFNN) and Neural Network trained with Genetic Algorithm (NNGA). The developed scheme for weld quality prediction is flexible, competent, and accurate than existing models and it scopes better online monitoring system. Finally the developed models are validated. The proposed and developed technique finds a good scope and a better future in the relevant field where human can avoid unwanted risks during operations with the deployment of robots.
\end{abstract}

\section{Keywords}

Submerged arc welding, Weld quality, Process parameters, Neural networks, Genetic algorithm

\section{Introduction}

Submerged Arc Welding is a widely used industrial arc welding process needs a better prediction and monitoring of its parameters to produce consistent weld quality. Weld quality plays an important role as it improves material strength, hardness and toughness of the product. Quality of a weld product is evaluated by different parameters like weld bead geometry, deposition rate, hardness etc. These characteristics are controlled by weld parameters like welding current, welding speed, arc voltage and electrode stick out. In order to attain good quality, is necessary to set the proper welding process parameters ${ }^{[1]}$. Researchers attempted many techniques to establish SAW process. The effects of welding variables upon bead shape and size ${ }^{[2]}$, bead width and height ${ }^{[3,4]}$, dilution and bead geometry ${ }^{[5]}$, weld deposit area ${ }^{[6]}$, element transfer behavior and weld-metal chemistry ${ }^{[7]}$ in submerged-arc welding was explored. Also the effect of increasing 
deposition rate on bead geometry ${ }^{[8]}$ and flux component on softening temperature was examined ${ }^{[9]}$ for submerged arc weld. Investigations were done to analyze the effect welding parameters on chemical composition and mechanical properties ${ }^{[10]}$, heat affected zone ${ }^{[11]}$ and bead geometry ${ }^{[12]}$ of submerged arc weld.

Usually, the desired welding parameters are determined using traditional methods like welder's experiences, charts and handbooks (preferred values) which are simple and inexpensive. But this does not ensure that the selected welding parameters result in satisfactory welding and this method is not applicable to new welding process. To overcome this problem, various methods of obtaining the desired output variables through models to correlate input variables with output variables have been developed.

Fractional factorial techniques ${ }^{[13]}$, Mathematical modeling ${ }^{[14]}$, curvilinear regression equations ${ }^{[15]}$, linear regression equations ${ }^{[16]}$, response surface methodology ${ }^{[17]}$, finite element modeling ${ }^{[18,19]}$, grey-based Taguchi method ${ }^{[20]}$ and sensitivity analysis ${ }^{[21]}$ were used to model SAW process. These methods are limited in application due to difficulties in modeling, time consuming and cumbersome. Due to the inadequacy and inefficiency of the mathematical models to explain the nonlinear properties existing between the input and output parameters of welding lead to the development of intelligent modeling techniques.

Precise simulation and analysis of the process needs attention which helps to predict the wide variety of process parameters to set the factory floor in real time. The type of artificial intelligence capable of responding to changes in the automated manufacturing environment, and having the ability to capture vast manufacturing knowledge is Artificial Neural Networks (ANN). It is becoming widely used in all aspects of manufacturing process to assist humans.

The main advantages of ANN are its adaptability, fault tolerant, noise resistant and its nonlinearity that can be useful to overcome industrial complex problems ${ }^{[22]}$ and employed where mathematical models are not available. Neural networks can manage noisy or incomplete data with ease, and that the process of information is distributed over the neurons, which operate in parallel resulting in increased computational power. ANN has the ability to learn complex relationship between the given set of input and output data. When presented with set of input and output pairs the network is able to learn the relationship between them by changing the weights of its interconnections ${ }^{[23]}$. The process of changing the weights is called training the networks. Once the network is trained, the weights will be frozen and that network can be used for prediction. ANN is also suitable for incremental learning; enabling the neural network models to be improved incrementally as new data become available ANN has been employed for optimization/resource allocation, pattern recognition and prediction ${ }^{[23-29]}$. ANN is used to predict weld quality ${ }^{[30]}$, angular distortions ${ }^{[31]}$ and process parameters of laser beam butt welding ${ }^{[32]}$. Data from multiple regression equations are also used to train ANN ${ }^{[33]}$. Multiphase propagation learning algorithm is widely used algorithm but it has a drawback of converging to a set of sub-optimal weights from which it cannot escape.

Radial Basis Function Neural network employs clustering of locating local hidden unit receptive field centers which achieves a performance comparable with back prop networks while requiring orders of magnitude less training time than back propagation algorithm. Since, the receptive field representation is well localized, only a small fraction of the hidden units in an RBFN network respond to any particular input vector. This allows the use of efficient self organization algorithms for adapting such units in a training mode that does not involve the network's output units. On the other hand all units in a back propagation network are evaluated and their weights updated for every input vector. Another important reason for faster training speed of RBFN networks is the hybrid two-stage training scheme employed, which decouples the learning task for both hidden and output layers, thus eliminating the need for the slow back error propagation ${ }^{[34]}$. Radial basis function neural network is successfully applied to predict quality in electrode discharge machining process ${ }^{[35]}$. Although neural networks are used for solving a variety of problems, they still have some limitations. One of the most common is associated with neural network training. Results form back-propagation ANN and radial basis function neural network cannot guarantee an optimal solution. 
Optimization tools like Particle Swarm Optimization (PSO) technique and Genetic algorithm are used as a powerful optimization tool. They offer an efficient search method for complex problem space and in various manufacturing process. Genetic algorithms are being attempted in guiding the weight updating process in the neural network technique ${ }^{[36,37]}$ and scopes to build fast, accurate predictive networks. GA is effectively applied with neural networks to predict machining forces ${ }^{[38]}$, predict weld residual stress ${ }^{[39]}$ and optimization of frictional vibration joining process ${ }^{[40]}$. PSO is used instead of backpropagation algorithm in neural network for the prediction of tool life ${ }^{[41]}$. PSO is applied to predict parameters to determine surface roughness ${ }^{[42]}$. This paper proposes the development of neural network models using backpropagation algorithm, radial basis function network, GA and PSO algorithm to predict weld quality in SAW process. The performance of the developed models are compared in terms of computational speed, accuracy and reported.

\section{Neural network models}

The use of neural network models is vital in the modern manufacturing environment. Neural networks are dynamic systems that consist of processing units called neurons with weighted connections to each other. Neural networks can learn, remember and retrieve data. The significant functions of neural network are tackling non-linearity and mapping input-output information. The different types of neural networks which are in practice are back propagation neural network, counter propagation neural network and radial basis function neural network. Each intelligent technique has certain strengths and weaknesses and they cannot be applied universally to every problem. This limitation is the central driving force behind the creation of intelligent hybrid systems where two or more techniques are combined in a manner that overcomes the limitations of individual techniques. The motivation for combining different intelligent techniques is multiplicity of application tasks, technique enhancement and realizing multifunctional tasks ${ }^{[23]}$. Hence optimization techniques like GA and PSO algorithms are employed in development of neural network models.

\subsection{Back propagation neural network model}

Back Propagation Neural Network (BPNN) is a multiple layer ANN with input layer, output layer and some hidden layers between the input and output layers. Its learning procedure is based on gradient search with least mean squared optimality criteria. Once the input data is fed to the nodes in the input layer $\left(\mathrm{o}_{\mathrm{i}}\right)$, this will be fed to nodes $(\mathrm{j})$ in the hidden layer through weighting factors $\left(\mathrm{w}_{\mathrm{ji}}\right)$. The net input to node $j$ is:

$$
\text { net }_{j}=\sum_{i} w_{j i} o_{i}-b_{j}
$$

Where $b_{j}$ is the bias over node $j$.

The output of the node $j$ :

$$
o_{j}=\frac{1}{1+e^{-n e t_{j}}}
$$

Similarly the outputs from nodes in the hidden layer are fed into nodes in the output layer. This process is called the feed forward stage. After feed forward, calculation output $\left(\mathrm{o}_{\mathrm{pk}}\right) \mathrm{can}$ be obtained from nodes in the output layer. In general, the output opk will not be the same as the desired known target tpk. Therefore the average system error is:

$$
E=\frac{1}{2 p} \sum_{p} \sum_{k}\left(t_{p k}-o_{p k}\right)^{2}
$$

The error is then back propagated from nodes in the output layer to nodes in the hidden layer using gradient search method 


$$
\Delta_{p} w_{k j}=-\eta \frac{\partial E}{w_{k j}}=\eta \delta_{k} o_{j}
$$

delta value for output layer is :

$$
\delta_{k}=o_{k}\left(1-o_{k}\right)\left(t_{k}-o_{k}\right)
$$

delta value for hidden value is:

$$
\delta_{j}=o_{j}\left(1-o_{j}\right) \sum w_{k j} \delta_{k}
$$

This process is called back propagation stage. After all examples are trained the system will collect adjusted weights according to:

$$
\Delta w_{j i}=\sum_{p} w_{j i}
$$

Updating of weights is done according to

$$
w_{j i}(n+1)=w_{j i}(n)+\Delta w_{j i}
$$

\subsection{Radial basis function neural network model}

RBFNN is a type of feed forward, multilayered network. It consists of three types of layers namely input, hidden and the output layers. The number of nodes in the input layer is equal to the dimension of the input vector and in the output layer it is equal to the dimension of the output vector. In the hidden layer, it is not fixed and it depends on the application. Each of the nodes in the input layer is connected to all the nodes in the hidden layer through unity weights while each of the hidden layer nodes is connected to all the output layer nodes through weights. The input layer nodes do not carry out any computation. The input nodes pass the incoming input vector to the hidden nodes. The connections between hidden nodes and the input nodes (first layer connections) are not weighted. The connections between hidden nodes and output nodes (second layer connections) are weighted and the output nodes are simple summations. Once the hidden units are synthesized, the second layer weights are computed by using the supervised normalized least mean square error rule. This procedure reduces the amount of computational time, since only the second layer weights are to be calculated using an error signal. The important aspect of RBFNN is the usage of activation function for computing the output. RBFNN uses Gaussian activation function. The response of such a function is non-negative for all values of $\mathrm{x}$. The function is defined as

$$
f(x)=\exp \left(-x^{2}\right)
$$

\subsection{Neural network model trained with genetic algorithm}

Genetic Algorithm is widely used to solve optimization problems. The standard genetic algorithm proceeds as follows: an initial population of individuals (that is, a set of solutions for the given problem represented by chromosomes) is generated at random or heuristically. The data is normalized in the range 0.1 to 0.9 by using the equation below

$$
x_{\text {norm }}=0.1+0.8\left[\frac{x_{i}-x_{\min }}{x_{\max }-x_{\min }}\right]
$$


The steps used in genetic algorithm are a) initializing the population randomly; b) cross over with probability c) mutation with probability. In each generation, the individuals in the current population are decoded and evaluated according to some predefined quality criterion, referred as the fitness function. To form a new population for next generation, the individuals are selected according to their fitness. The selected best population will undergo crossover and mutation operation to produce new offspring's. Then some or all population are replaced with newly created offspring based on their fitness. This action is motivated by a hope that the new population will be better than the old one. This is repeated until some condition (for example number of populations or improvement of the best solution) is satisfied. If GA has been designed well, the population will converge to an optimal solution to the problem.

\subsection{Neural network model trained with particle swarm optimization}

In this model, back propagation algorithm of neural network is replaced by PSO algorithm. Here the randomly generated weights are assigned in each link of neural network. In particle swarm optimization algorithm, PBest is the location of the best solution of a particle has achieved so far. GBest is the location of the best solution that any neighbor of a particle has achieved so far. Initially random numbers are generated for each particle and these random values are considered as PBest and present weights. Velocity is calculated using the equation 3 and added with the present weight in each link of neural network. For each particle, the newly calculated weights are compared with the PBest weights and the minimum error produced weights are stored in PBest. Initial velocity V is assumed to be 1 and GBest is the weights of minimum error produced particle. New weight is calculated in equation 4.

$$
\begin{gathered}
\text { Velocity }[]=w \text { Velocity }[]+C_{1} \operatorname{rand}_{1}(\text { PBest }[]-\text { present }[])+C_{2} \operatorname{xrand}_{2}(\text { GBest }[]-\text { present }[]) \\
\text { Present }[]=\text { Present }[]+\text { Velocity }[]
\end{gathered}
$$

where $\mathrm{C}_{1}$ and $\mathrm{C}_{2}$ are two positive constants named learning factors. Rand $_{1}$ and rand $_{2}$ are two random functions in the range $[0,1] . \mathrm{w}$ is an inertia weight to control the impact of the previous history of velocities on the current velocity. The operator w plays the role of balancing the global search and the local search; and was proposed to decrease linearly with time from a value of 1.4 to 0.5 . As such, global search starts with a large weight and then decreases with time to favor local search over global search. When the number of iterations is equal to the total number of particles, goal is compared with the error produced by the GBest weights. If the error produced by the GBest weights are less than or equal to the goal, weights in the GBest are used for testing and prediction. Otherwise weights of minimum error are stored in GBest and the iterations are repeated until goal reached.

\section{Problem definition}

Relationship between welding current, arc voltage, welding speed and electrode stick out are established for any welding operations. Influence of these parameters on the weld quality is found by experimentation. But, in practice experimentation is laborious and cumbersome. The other traditional method of representing the interplay of these parameters and their effect on quality of weld has been by developing empirical relations in which the parameters have some constant exponents whose value is chosen/estimated on the basis of experience. This choice of the exponents introduces a lot of subjectivity and is fixed. It is difficult to relate the choice of these exponents to the changing weld conditions. The evolution and use of equations for each objective limits the application of multiple regressions as a predictive method. The objective of this research is to predict the quality of weld in terms of weld bead width, weld reinforcement, depth of penetration and bead hardness for various process parameters by capturing the real welding conditions and using them to develop a generalized model, which is for predicting the output for the unknown input parameters. 


\section{Data acquisition}

Experiments were carried out by Taguchi's design of experiments using L8 orthogonal array. Number of factors involved is four and number of levels is two. Experiments were conducted using semiautomatic SAW machine (SURARC of type XRCP 1200). Experiment was conducted at M/s. Ind Auto Products, Tiruchirappalli, Tamilnadu, India as shown in Figure 1. Two mild steel plates of IS 2062 grade $(0.25 \% \mathrm{C}, 0.20 \% \mathrm{Si}, 0.75 \% \mathrm{Mn}$ and balance $\mathrm{Fe})(500 \mathrm{~mm} \times 50 \mathrm{~mm} \times 6 \mathrm{~mm})$ were welded with a square butt joint at a single pass in a SAW machine keeping the electrode positive perpendicular to the plate. Electrode dia, $3.15 \mathrm{~mm}$, AWS ER70S-6 was utilized to weld. Samples (width, 10mm) were cut from the test piece as shown in Figure 2. Specimens were cleaned, polished and etched. Profile projector was used to measure weld bead geometry (bead width, bead reinforcement and depth of penetration). Hardness on the weld bead was found by Rockwell hardness testing machine on $\mathrm{C}$ scale. A load of $150 \mathrm{KgF}$ was applied on the cross section of the weld bead for few seconds using diamond intender. The observed values from the specimens are given in Table 1.

Table 1. Measured values from experimentation

\begin{tabular}{llllllll}
\hline I & V & S & E & $\begin{array}{l}\text { Average bead } \\
\text { width, mm }\end{array}$ & $\begin{array}{l}\text { Average bead } \\
\text { reinforcement, mm }\end{array}$ & $\begin{array}{l}\text { Average depth of } \\
\text { penetration, mm }\end{array}$ & $\begin{array}{l}\text { Average bead hardness, } \\
\text { HRC }\end{array}$ \\
\hline 360 & 25 & 400 & 19 & 13.0 & 2.0 & 3.0 & 37 \\
360 & 25 & 400 & 25 & 11.0 & 2.0 & 3.5 & 40 \\
360 & 26 & 420 & 19 & 12.5 & 3.0 & 3.5 & 42 \\
360 & 26 & 420 & 25 & 13.5 & 1.5 & 4.0 & 34 \\
390 & 25 & 420 & 19 & 14.5 & 2.0 & 5.0 & 52 \\
390 & 25 & 420 & 25 & 14.0 & 2.5 & 4.5 & 48 \\
390 & 26 & 400 & 19 & 14.5 & 2.0 & 4.0 & 49 \\
390 & 26 & 400 & 25 & 15.0 & 3.0 & 3.5 & 48 \\
\hline
\end{tabular}

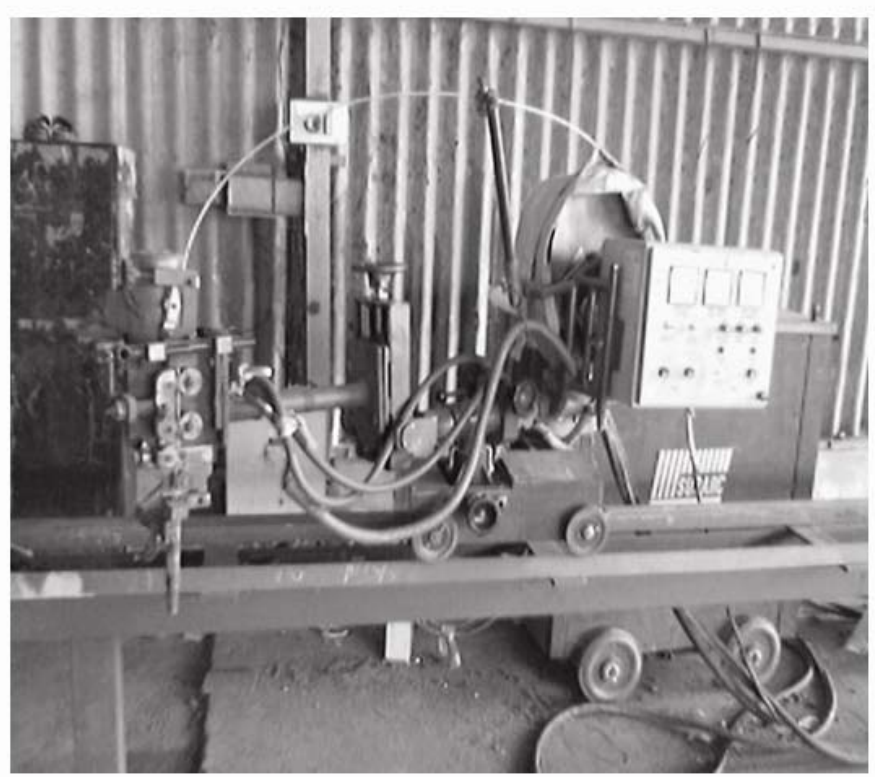

Figure 1. SAW equipment used for experimental study 

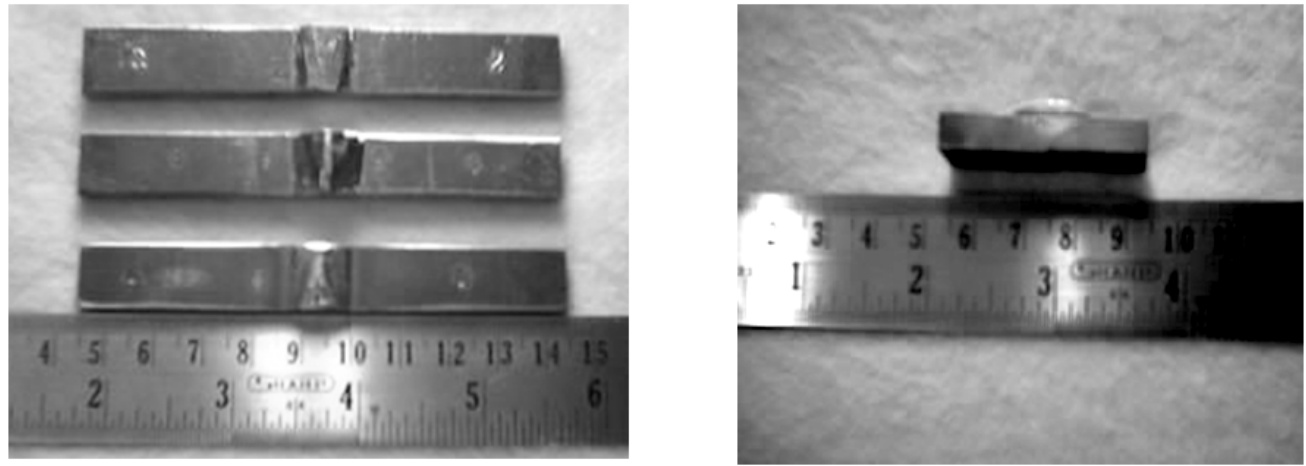

Figure 2. Typical photographic view of weld samples

The dependency of weld quality to welding current, arc voltage, welding speed and electrode stick out is established using the multiple regression equations as shown below.

Weld bead width in $\mathrm{mm}=-34.833+(6.667 \times 10-2 \times$ welding current $+(0.750 \times$ arc voltage $)+(1.25 \times 10-2 \times$ welding speed $)$

- $(4.17 \times 10-2 \times$ electrode stick-out $)$

Weld bead reinforcement, $\mathrm{mm}=-7.25+(8.33 \times 10-3 \times$ welding current $)+(0.25 \times$ arc voltage $)$

Depth of penetration, $\mathrm{mm}=16.25+(2.500 \times 10-2 \times$ welding current $)-(0.25 \times$ arc voltage $)-(3.75 \times 10-2 \times$ welding speed $)$

Weld bead hardness, $\mathrm{HRC}=-69.333+(0.367 \times$ welding current, $)-(1.000 \times$ arc voltage $)+(2.5 \times 10-2 \times$ welding peed $)-$ $0.417 \times$ electrode sickout)

From the above equations, thirty new values of weld bead width, weld bead reinforcement, depth of penetration and weld bead hardness are generated and are used with data's from Table 1 to train the various proposed neural network models.

\section{Development of proposed Neural Network Models}

To handle multiplicity of application tasks and realizing multi-functionality different neural network models are proposed and developed.

\subsection{Development of BPNN model}

Topography of the developed to predict weld bead geometry and hardness is shown in Figure 3. It is feed forward back propagation network trained with Levenberg-Marquardt back propagation algorithm. Experimental data supported with data generated from regression models is used for training and testing the developed BPNN model. The learning function is gradient descent algorithm with momentum weight and bias learning function. The number of hidden layers and neurons are determined through a trial and error method, in order to accommodate the converged error. The structure of the developed neural network is 4-12-9-4 (4 neurons in the input layer, 12 neurons in 1st hidden layer and 9 neurons in 2nd hidden layer and 4 neurons in the output layer). With a learning rate of 0.55 and a momentum term of 0.9 , the network is trained for 10000 iterations. The error between the desired and the actual outputs is less than 0.001 at the end of the training process. 


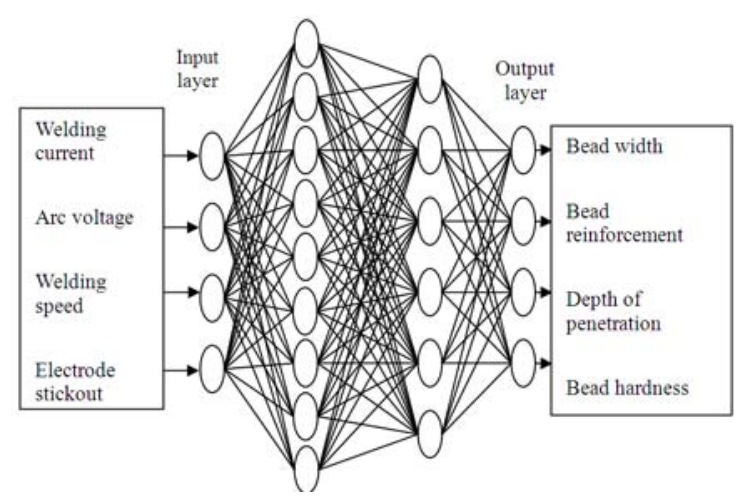

Figure 3. Developed structure of BPNN model

\subsection{Development of RBFNN model}

Flow chart in Figure 4 shows the stages involved in development of the RBFNN model for weld quality prediction. The data required for training and testing the radial basis function neural network model is taken from the experimental data in Table 1 supported with data from regression analysis. The computations involved in RBFNN are given below. Each hidden unit's output is obtained by calculating the closeness of the input $x$ to an $n$-dimensional parameter $\mu \mathrm{j}$ with the $\mathrm{jth}$ hidden unit. The net input to the $\mathrm{jth}$ radial basis neuron is given in the equation (9) where $\mathrm{x}$ is the input vector and $\mathrm{b}_{\mathrm{j}}$ is $\mathrm{a}$ fixed function of the width of the respective field $\sigma_{j}$ as given in the equation (10).

$$
\begin{gathered}
y_{j}(x)=b_{j}\left(\left\|x-\mu_{j}\right\|\right) \\
b_{j}=\sqrt{(-10 g 0.5) / \sigma_{j}}
\end{gathered}
$$

The output of the $\mathrm{jth}$ radial basis neuron is given in the equation (11)

$$
z_{j}(x)=\exp \left(-\left(y_{j}(x)\right)^{2}\right)
$$

The output value $\mathrm{O}_{\mathrm{k}}(\mathrm{X})$ of the kth output node is equal to the sum of the weighted outputs of the hidden nodes and the bias of the kth output node is given in the equation (12).

$$
\mathrm{O}_{\mathrm{h}}(X)=\mathrm{w}_{\mathrm{hj}} z_{\mathrm{j}}+\mathrm{bia}_{\mathrm{k}}
$$

The error (E) is calculated as in equation (13) where $\mathrm{O}^{\mathrm{D}}{ }_{\mathrm{k}}$ is the desired output at the kth node and $\mathrm{O}^{\mathrm{R}}$ is the $\mathrm{RBFNN}$ output at the kth node.

$$
E=\sum_{\mathrm{k}=1}^{\mathrm{t}}\left(\mathrm{O}^{\mathrm{D}} \mathrm{k}-\mathrm{O}_{\mathrm{k}}^{\mathrm{k}}\right)
$$

The weights are updated as in equation (14) where $y^{\prime}(t)$ is the transpose of $y(t)$ and $(\eta)$ is learning parameter.

$$
w(t+1)=w(t)+\tau(t) y(t) /\left(y^{\prime}(t) y(t)\right)
$$




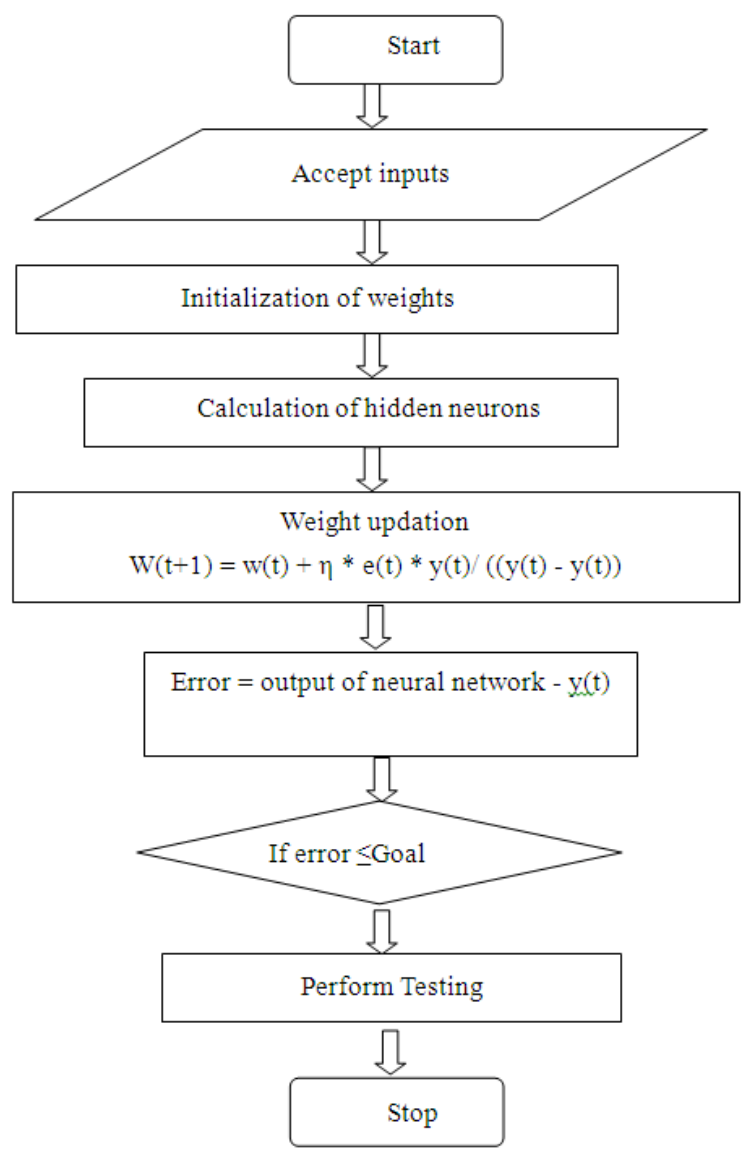

Figure 4. Development of the RBFNN model for weld quality prediction

In RBFNN the learning parameter is kept constant. But for adaptive problems it is always needed to change the learning parameter for all the iterations. Increasing or decreasing learning parameter by trial and error method is not an efficient one. So a systematic variation of learning parameter is called for. The error (e) and change in error (ce) are the parameters based upon which learning parameter is changed.

\subsection{Development of NNGA model}

The proposed method is to predict weld quality using NNGA model is depicted in Figure 5. Neural network model proposed to capture welding characteristics is shown in Figure 3. The topology of a neural network is defined and will remain fixed after the initialization. The learning function is gradient descent algorithm with momentum weight and bias learning function. The parameters used for developing NNGA model is shown in Table 2. The error between the desired and the actual outputs is less than 0.001 at the end of the training process. The transfer function and error criteria (mean square error) are fixed. Training is done by genetic algorithm search. In this application each string or chromosome in the population represents the weight and bias values of the network. The initial population is randomly generated. By selecting suitable parameters like selection criteria, probability of crossover, probability of mutation, initial population etc., to the GA, high efficiency and performance is achieved. The objective function is minimization of the mean square error calculated using equation (15).

$$
O b j=\frac{1}{2 p} \sum_{p} \sum_{k}(T-O)^{2}
$$




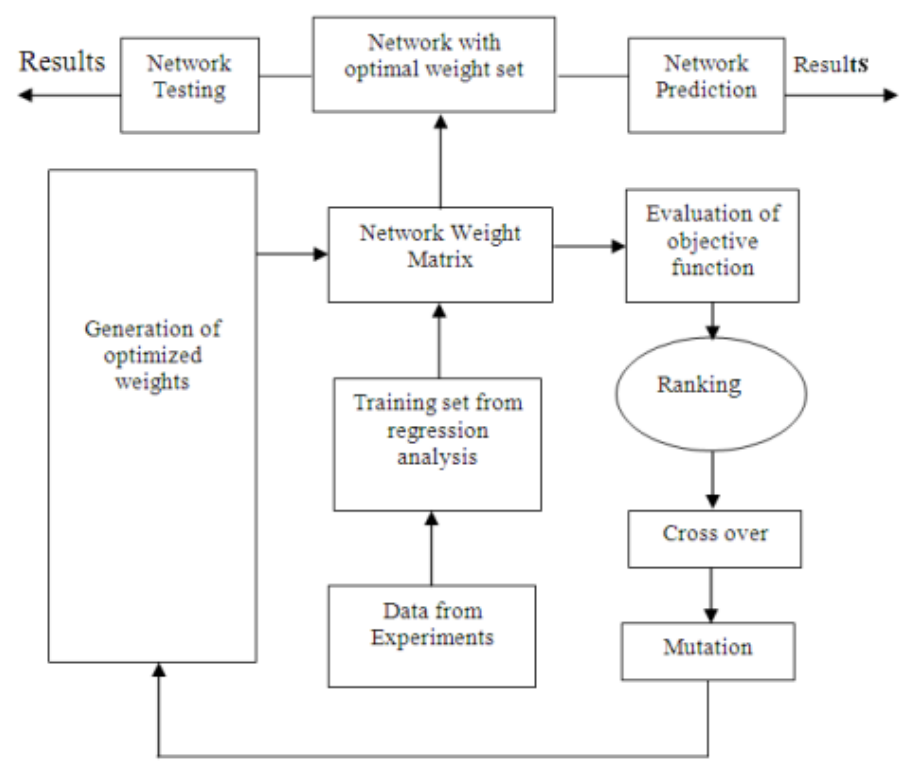

Figure 5. NNGA model for weld quality prediction

Table 2. Parameters used for developing NNGA model

\begin{tabular}{ll}
\hline Parameters & Value \\
\hline Network and transfer functions & $\begin{array}{l}\text { One hidden-5 neurons-log sigmoid } \\
\text { Output layer }-4 \text { neurons - purelin }\end{array}$ \\
No of training data sets & 31 \\
No of testing data & 5 \\
Fitness function & Mean squared error \\
Population size & 40 \\
Stopping criteria & 150 Iterations \\
Selection & Best half of the population \\
Crossover & Pc $=0.9$ \\
Mutation & Pm $=0.07$ \\
\hline
\end{tabular}

Fitness function considered is the minimum of the mean square error and computed by recalling the network. After getting the fitness values of all chromosomes, they are ranked based on the best fitness values. For the production of offspring for next generation half of the best-ranked population is selected. This half population undergo crossover with crossover probability $(\mathrm{Pc})$. This again will be mutated to give a new offspring, with mutation probability (Pm), which is combined with selected best population to form a new population for the next generation. Typical neural network model with 4-5-4 architecture with weights is depicted in Figure 6 . Where $\mathrm{X} 1, \mathrm{X} 2, \ldots$ are inputs and $\mathrm{Y} 1, \mathrm{Y} 2, \ldots$ are outputs. This will be continued till the stopping criteria are reached. The stopping criteria for this network are the number of generations. Neural network coded with optimal weight set chromosome produced by genetic algorithm is forwarded to predict the quality of weld. 

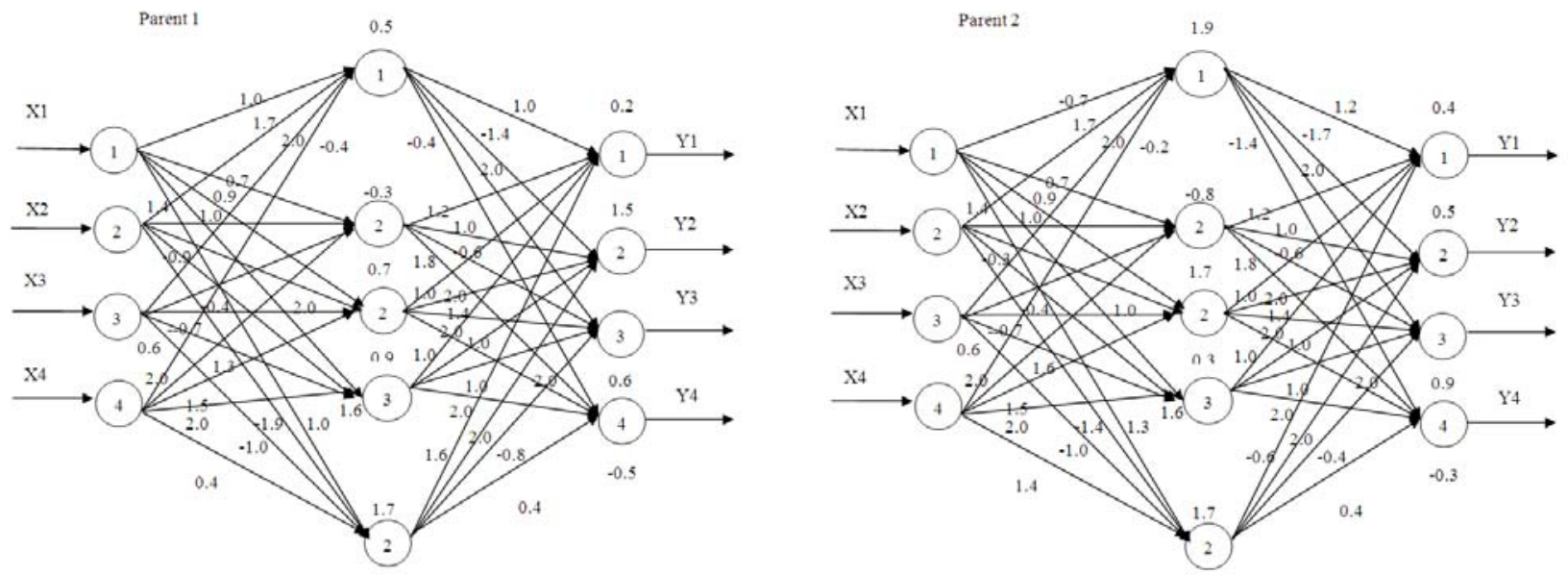

Figure 6. A Typical neural network model coded with weights

\subsection{Development of NNPSO model}

The data required for training and testing the NNPSO model is taken from the experimental data in Table 1 supported with data from regression analysis. In this model, back propagation algorithm of neural network is replaced by PSO algorithm. PSO algorithm is used to train the neural network as shown in Figure 7. Parameters used for PSO computations are shown in Table 3.

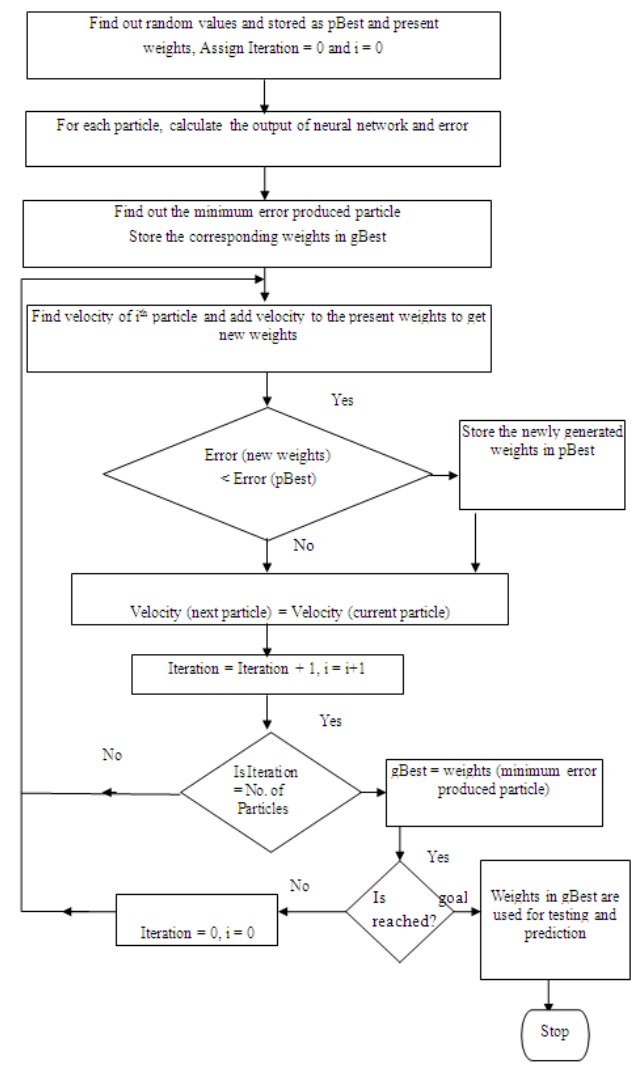

Figure 7. Flowchart for training the neural network using PSO algorithm 
Table 3. Parameters used for PSO computations

\begin{tabular}{|l|l|}
\hline Population size & 40 \\
\hline Dimension size & 4 \\
\hline Inertia weight & $0.5-1.4$ \\
\hline $\begin{array}{l}\text { Number of iterations } \\
\text { allowed }\end{array}$ & Total number of particles \\
\hline Velocity factors, $\mathrm{C}_{1}$ and $\mathrm{C}_{2}$ & 1.4 \\
\hline
\end{tabular}

\section{Results and discussions}

Success and failure of an industry depends on effective and efficient decision making process. Effective decision making process depends on intelligent decision making tools. Hence development of efficient decision making tools is necessary for any process. This paper elaborates the methodology to choose the best intelligent decision making tool for achieving quality weld. Experiments are conducted in SAW machine using Taguchi's principles. Results from experimentation are used to generate more sets of data from multiple regression models. To determine the accuracy of the developed mathematical models, R2 -value is computed, which is more than 0.8. It shows high coefficient of correlation. Experimental data along with data from regression models are used to train and test the proposed neural network models. Results of the developed models are compared with experimental results with the help of scatter plots shown from Figures 8 - 11. Microscopic tests are conducted on the confirmation experiment test samples to ensure the quality of weld material. It is noted that the heat affected zones in all welds is tedious to observe with optical microscope even after the metallographic etching. It revealed that there is small difference in corrosion rates among the fusion zone and heat affected zone, or heat affected zone and base metal as the weld was immersed in the etchant. SEM micrographs of the metallographically etched welds are presented in Figures 13 and 14. The images of heat affected zones were relatively dark, compared with their adjacent fusion zones and base metal in which high bright image of precipitates can be found along their grain boundaries. Some $\delta$ - precipitates with an elongated lath shape are observed in the base metal, and intermetallic laves phases, $\sigma$ - precipitates, with a nodular shape in the fusion zones. High bright image of these precipitates observed by SEM was attributed to charge concentration on the precipitates and their outstand appearance. The SEM image of as-received base metal was like the image of heat affected zone, dark and smooth. Thus, it is difficult to differentiate the region or even the existence of the heat affected zone in the as-received weld with SEM observation. Since $\delta$-precipitates are presented along the grain boundaries of weld metal in solution and precipitation-pretreated welds, but not in as-received weld.

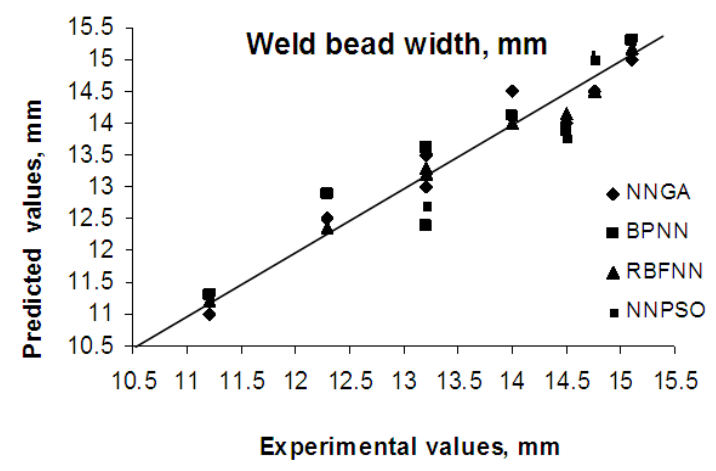

Figure 8. Comparison of weld bead width 


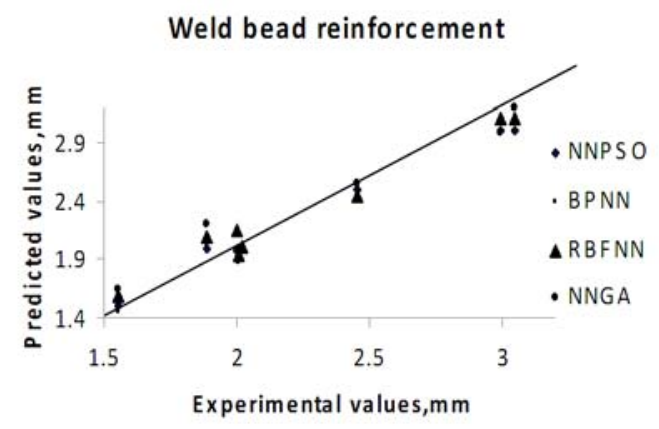

Figure 9. Comparison of weld bead reinforcement

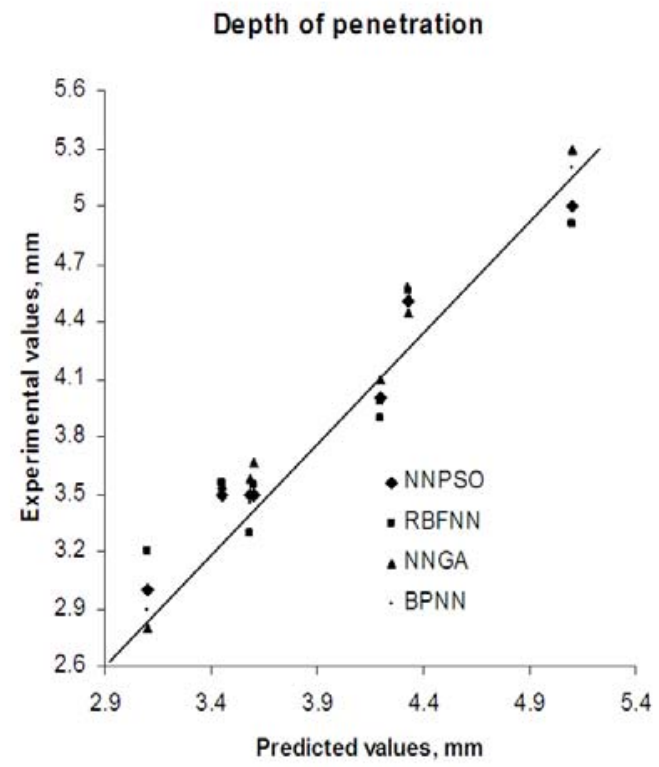

Figure 10. Comparison of depth of penetration

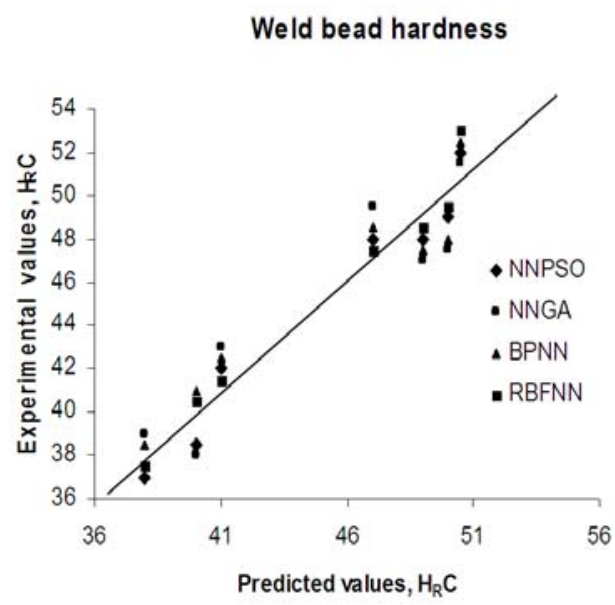

Figure 11. Comparison of weld bead hardness

The performance of the developed models is measured in terms of the computational time and accuracy. 


\subsection{Model accuracy}

Confirmatory tests are done to validate this approach. Table 4 shows the outcomes from confirmatory tests. Among the developed neural network models, the predictive error for the network using PSO is less compared with other models. The developed neural network model with PSO predicts the output with an accuracy of error hardly less than $2 \%$. The percentage of error predicted by the developed models are calculated by [\{Observed value- predicted value $\} /$ predicted value] $\times 100$ as shown from Tables 5-8.

Table 4. Results from the confirmatory experiments

\begin{tabular}{llllllll}
\hline \multicolumn{7}{l}{ Process parameters } & \multicolumn{2}{l}{ Experimental values } \\
\hline I & V & S & E & $\begin{array}{l}\text { Average bead } \\
\text { width, } \mathbf{~ m m}\end{array}$ & $\begin{array}{l}\text { Average bead } \\
\text { reinforcement, } \mathbf{~ m m}\end{array}$ & $\begin{array}{l}\text { Average depth of } \\
\text { penetrationmm }\end{array}$ & $\begin{array}{l}\text { Average bead } \\
\text { hardnessH }\end{array}$ \\
\hline 390 & 26 & 410 & 19 & 14.7 & 2.50 & 4.25 & 51.0 \\
370 & 25 & 420 & 21 & 12.5 & 2.00 & 3.50 & 43.0 \\
380 & 26 & 400 & 25 & 14.0 & 2.50 & 4.25 & 44.5 \\
360 & 26 & 400 & 19 & 13.0 & 2.25 & 3.75 & 40.0 \\
\hline
\end{tabular}

Table 5. Results from the confirmatory experiments

\begin{tabular}{llll}
\hline \multicolumn{2}{l}{ Percentage error of weld bead width predicted by } & & \\
\hline BPNN model & $\begin{array}{l}\text { RBFNN } \\
\text { Model }\end{array}$ & NNGA model & NNPSO model \\
\hline-2.00 & -4.36 & -2.13 & -0.13 \\
-1.64 & -0.856 & -0.06 & 0.096 \\
-1.47 & 1.383 & -1.47 & -2.09 \\
4.083 & -3.86 & 3.817 & -0.95 \\
\hline
\end{tabular}

Table 6. Percentage error of weld bead reinforcement

\begin{tabular}{llll}
\hline \multicolumn{2}{l}{ Percentage error of weld bead reinforcement predicted by } & \\
\hline BPNN model & $\begin{array}{l}\text { RBFNN } \\
\text { Model }\end{array}$ & NNGA model & NNPSO model \\
\hline 3.03 & -7.33 & -3.69 & 1.65 \\
-5.25 & -5.70 & 0.100 & 0.057 \\
2.79 & 7.99 & -2.837 & -0.234 \\
1.323 & -5.93 & -8.312 & -0.310 \\
\hline
\end{tabular}

Table 7. Percentage error of depth of penetration

\begin{tabular}{llll}
\hline \multicolumn{2}{l}{ Percentage error of depth of penetration predicted by } & \\
\hline BPNN model & RBFNN & & \\
& Model & NNGA model & NNPSO model \\
\hline 3.03 & 2.533 & -2.52 & -0.70 \\
2.10 & -0.28 & 1.596 & 0.057 \\
-0.234 & -6.87 & -5.91 & -0.23 \\
1.323 & -0.079 & 6.92 & -1.35 \\
\hline
\end{tabular}


Table 8. Percentage error of bead hardness

\begin{tabular}{llll}
\hline \multicolumn{2}{l}{ Percentage error of bead hardness predicted by } & & NNPSO model \\
\hline BPNN model & $\begin{array}{l}\text { RBFNN } \\
\text { Model }\end{array}$ & NNGA model & 1.75 \\
\hline-2.1 & -0.29 & 2.02 & 0.70 \\
2.25 & 2.87 & -2.2 & 1.159 \\
-2.6 & -0.92 & -0.08 & -0.89 \\
\hline .41 & 4.32 & 1.60 & \\
\hline
\end{tabular}

\subsection{Computational time}

Time required for training the developed network models are compared in terms of number of epochs shown in Figure 12. The configurations of the computing machine used are Intel Pentium IV $1.8 \mathrm{GHz}$ processor, $512 \mathrm{MB}$ RAM and $80 \mathrm{~GB}$ Hard Disk Drive. Results indicate that the developed ANN model trained with PSO needs minimum number of epochs and hence computational time required is less. NNPSO model gives optimal results than the other developed neural network models as shown in Figure 12. The reason is that NNPSO model searches solution in the search space different from other neural network models. It maintains an internal memory to store the Gbest and Pbest solutions. Each individual in the population tries to emulate the Gbest and Pbest solutions in the memory through updating by two PSO equations. But NNGA model iteratively searches for several good individuals in the population, and make the population to emulate the best solutions found in that generation through reproduction, crossover and mutation operators. Hence it requires substantial computational time to perform decision making whereas back propagation algorithm training, radial basis function neural network may converge to a set of sub-optimal weights. Hence the effectiveness of NNPSO model in finding the true global optimal solution is competent than the other neural network models.

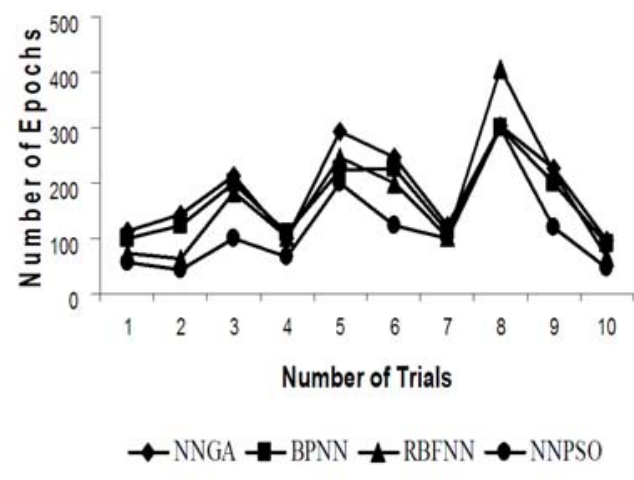

Figure 12. Comparison of performance of developed models for predicting weld quality
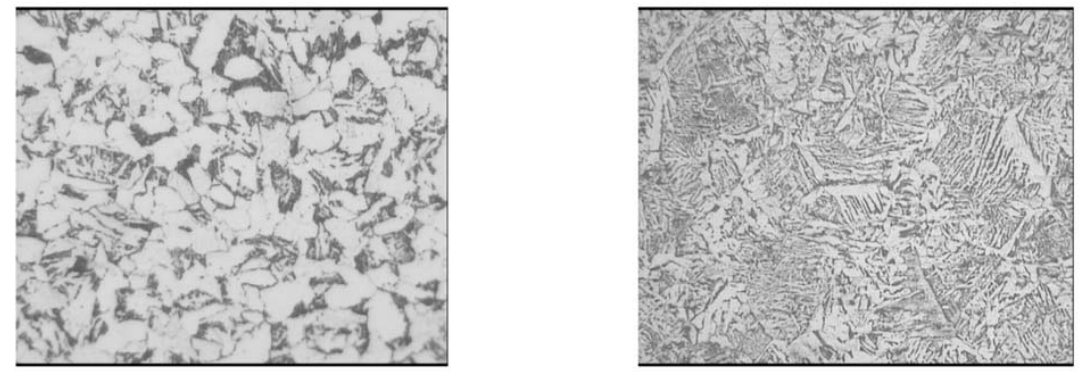

Figure 13. Metallographic view for base metal and heat affected zone 

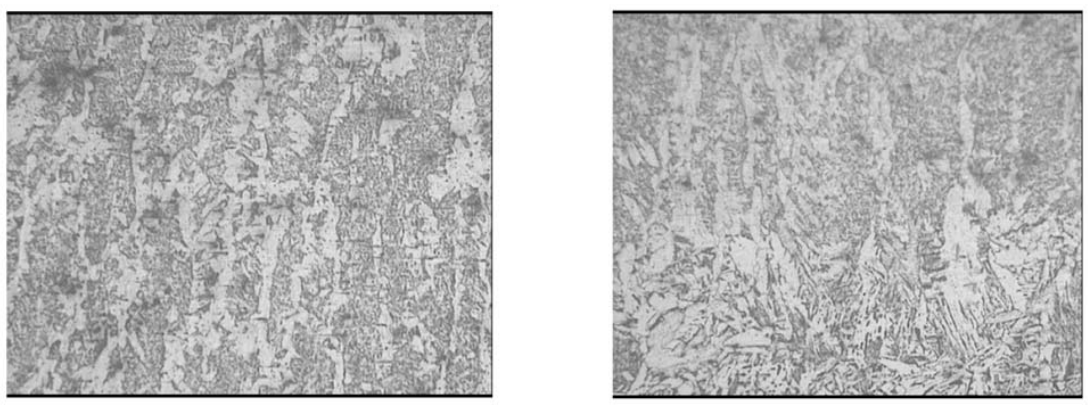

Figure 14. Metallographic view for fusion zone and fusion zone with heat affected zone

\section{Conclusions and future work}

The following conclusions are drawn from the work.

Taguchi method is effectively applied for experimentation. Relationship between the input weld parameters weld bead width, weld reinforcement, depth of penetration and bead hardness and output weld parameters are modeled through regression analysis and additional data's are generated to train the neural network models.

Validity of the developed equations is checked for adequacy. It is found that the result from neural network trained with PSO seems to have an edge over the other developed models in terms of computational accuracy and time. Confirmative experiments are done for validation. The developed model scopes for online weld quality monitoring system. To ensure high quality of welding SEM analysis is done on the weld samples indicating a good grain structure.

The developed system can be made as an in-process weld quality prediction system by interfacing the SAW equipment with a computer / laptop. The proposed technique provides manufacturers to develop intelligent manufacturing system to achieve the highest level of automation.

\section{References}

[1] Nadkarni S.V. Modern Welding Technology. New Delhi: Oxford and IBH Publishing Co. Pvt. Ltd. 1988.

[2] Apps, R.L. Gourd, L.M. Lelson, K.A. Effect of welding variables upon bead shape and size in submerged-arc welding. Welding and Metal Fabrication. 1963; 31: 453-457.

[3] Yang, L.J. Chandel, R.S. Bibby, M.J. The effects of process variables on the bead width of submerged arc weld deposits. Journal of Materials Processing Technology. 1992; 29(1-3): 133-144.

[4] Yang, L.J. Chandel, R.S. Bibby, M.J. The effects of process variables on the bead height of submerged-arc weld deposits. Canadian Metallurgical Quarterly. 1992; 31(4): 289-297.

[5] Murugan, N., Parmar, R. S. Sud, S. K. Effect of submerged arc welding process variables on dilution and bead geometry in single wire surfacing. Journal of Materials Processing Technology. 1993; (37): 767-780.

[6] Yang, L.J Chandel, R.S.Bibby, M.J. The effects of process variables on the weld deposit area of submerged arc welds. Welding Journal. 1993; 72 (1): 11-18.

[7] Pandey, N.D. Bharti, A. Gupta, S.R. Effect of submerged arc welding parameters and fluxes on element transfer behavior and weld-metal chemistry. Journal of Materials Processing Technology. 1994; 195-201.

[8] Chandel, R.S. Seow, H.P.Cheong, F.L. Effect of increasing deposition rate on the bead geometry of submerged arc welds. Journal of Materials Processing Technology. 1997; 72 (1): 124-128.

[9] Shao-huaSui., Wei-weiCai., Zhi-qiang Liu, Tian-ge Song, \& An Zhang. Effect of Submerged Arc Welding Flux Component on Softening Temperature. International Journal of Iron and Steel Research. 2006; 13(2): 65-68. http://dx.doi.org/10.1016/S1006-706X(06)60047-2. 
[10] Kanjilal, P. Pal, T.K. Majumdar, S.K. Combined effect of flux and welding parameters on chemical composition and mechanical properties of submerged arc weld metal. Journal of Materials Processing Technology. 2006; 171(2): 223-231.

[11] Rajesh Kumar. Rupinder Singh. Effect of process variables on HAZ in submerged arc welds of structural pipes. Central Manufacturing Institute. 2007; 6(4): 23-30.

[12] Edwin Raja Dhas, J.Kumanan, S. Effects of Process parameters in bead geometry and hardness in submerged arc weld on mild steel. National Journal of Technology. 2010; 6(2): 66-74.

[13] Gupta, V. K. Parmar, R. S. Fractional factorial techniques to predict dimensions of the weld bead in automatic submerged arc welding. Journal of Institution of Engineers. 1986; (70): 67-71.

[14] Chandel, R.S. Mathematical modeling of melting rates for submerged arc welding. Welding Journal. 1987; 66 (5): $135-140$.

[15] Yang, L.J. Chandel, R.S. An analysis of curvilinear regression equations for modeling the submerged-arc welding process. Journal of Material Processing Technology. 1993; (37): 601-611.

[16] Yang, L.J. Chandel, R.S. Bibby, M.J. Linear regression equations for modeling the submerged-arc welding process. Journal of Materials Processing Technology. 2003; 39 (1-3): 33-42. http://dx.doi.org/10.1016/0924-0136(93)90006-R.

[17] Gunaraj, V. Murugan, N. Application of response surface methodology for predicting weld bead quality in submerged arc welding of pipes. Journal of Materials Processing Technology. 1999; 88 (15): 266-275. http://dx.doi.org/10.1016/S0924-0136(98)00405-1

[18] Wen, S.W. Hilton, P Farrugia, D. C. J. Finite Element Modeling of Submerged arc welding process. Journal of Material Processing Technology. 2001; (119): 203-209. http://dx.doi.org/10.1016/S0924-0136(01)00945-1

[19] Syrcos, G.P. Die casting process optimization process using Taguchi methods. Journal of Materials Processing Technology. 2003; (135): 68-74. http://dx.doi.org/10.1016/S0924-0136(02)01036-1.

[20] Tarng, Y.S. Juang, S.C. Chang, C. H. The use of grey-based Taguchi methods to determine submerged arc welding process parameters in hardfacing. Journal of Materials Processing Technology. 2002; (128): 1-6. http://dx.doi.org/10.016/S0924-0136(01)01261-4.

[21] SerdarKaraoglu. Abdullah Secgin. Sensitivity analysis of SAW process parameters. Journal of Materials Processing Technology. 2008; 202: 500-507. http://dx.doi.org/10.1016/j.jmatprotec.2007.10.035.

[22] Zhang, H.C. Huang, S.H. Application of neural networks in manufacturing: a state of the art survey. International Journal of Production Research. 1995; (33): 705-728.

[23] Goonatilake, S., Khebbal, S. Intelligent Hybrid System. John Wiley and Sons, New York. 1995.

[24] Nagesh, D.S. Datta, G.L. Prediction of weld bead geometry and penetration in shielded metal-arc welding using artificial neural network .Journal of Material Processing Technology. 2002; (123): 303-312. http://dx.doi.org/10.1016/S0924-0136(02)00101-2.

[25] Kim, I.S. Son, J.S. Park, C.E. Lee, C.W. Yarlagadda. Prasad, K.D.V. A study on prediction of bead height in robotic arc welding using a neural network. Journal of Material Processing Technology. 2002; (131): 229-234. http://dx.doi.org/10.1016/S0924-0136(02) 00803-8.

[26] HasanOkuyucu., Adem Kurt. Erol Arcaklioglu. Artificial neural network applications to the friction stir welding of aluminum plates. Materials and Design. 2007; 28: 78-84. http://dx.doi.org/10.1016/j.matdes.2005.06.003.

[27] Edwin Raja Dhas, J. Kumanan, S. Prediction of weld bead width using artificial neural networks Proceedings of Factory Automation. Robotics and Soft computing, National Institute of Technology, Warangal, India. 2007; 382-385.

[28] AzlanMohdZain, HabibollahHaron, Safian Sharif. Prediction of surface roughness in the end milling machining using Artificial Neural Network. Expert Systems with Applications. 2010; (37): 1755-1768. http://dx.doi.org/10.1016/j.eswa.2009.07.033.

[29] Yahia, N.B Belhadj, T. Brag, S.Zghal A. Automatic detection of welding defects using radiography with a neural approach, Procedia Engineering. 2011; (10): 671-679. http://dx.doi.org/10.1016/j.proeng.2011.04.112.

[30] BappaAcherjee, SubrataMondal, BipanTudu, DiptenMisra. Application of artificial neural network for predicting weld quality in laser transmission welding of thermoplastics. Applied Soft Computing. 2011; 11(2): 2548-2555. http://dx.doi.org/10.1016.

[31] SeyyedianChoobi, M., Haghpanahi, M. Sedighi M. Prediction of welding-induced angular distortions in thin butt-welded plates using artificial neural networks. Computational Materials Science. 2012; (62): 152-159. http://dx.doi.org/10.1016.

[32] Sathiya, P. Panneerselvam, K. Abdul Jaleel M.Y. Optimization of laser welding process parameters for super austenitic stainless steel using artificial neural networks and genetic algorithm, Materials and Design. 2012; (36): 490-498. http://dx. doi.org/10.1016.

[33] Eskandari, H., Rezaee, M. R. Mohammadnia, M. Application of multiple regression and artificial neural networks techniques to predict shear wave velocity from wireline log data fora carbonate reservoir. CSEG recorder, south west Iran. 2004; (42): 40-48.

[34] Mohamad Hassoun, H. Fundamentals of Artificial Neural Networks. New Delhi: Prentice Hall of India Private limited. 2007.

[35] Rahman, M.M. Modeling of machining parameters of Ti-6Al-4V for electric discharge machining: A neural network approach, Scientific Research and Essays. 2012; 7(8): 881-890.

[36] Schaffer, J.D. Whitely, D. Eshelman, L.J. Combinations of Genetic Algorithms and Neural Networks: A Survey of the State of the Art, Proceedings of the IEEE Workshop on combinations of genetic algorithm and neural networks. 1992; 1-32. 
[37] Philipp Koehn. Combining Genetic Algorithms and Neural Networks. The Encoding Problem, A Thesis Presented for the Master of Science Degree, The University of Tennessee, Knoxville. 1994.

[38] Kumanan, S. Nannae Sahib, S.K. Jesuthanam, C.P. Prediction of Machining Forces using Neural Networks Trained by a Genetic Algorithm. Journal of the Institute of Engineering. 2006; (87): 11-15.

[39] Kumanan, S. Edwin Raja Dhas, J. Ashok Kumar, R.. Development of Welding Residual Stress Predictor using a FunctionReplacing Hybrid System. International Journal of Advanced Manufacturing Technology. 2007; (31): 1083-1091. http//dx.doi.10.1007/s00170-005-0297-1

[40] Panneerselvam, K. Aravindan, S. NoorulHaq, A. Hybrid of ANN with genetic algorithm for optimization of frictional vibration joining process of plastics. International Journal of Advanced Manufacturing Technology. 2009; (42): 669-677. http//dx.doi.org/10.1007/s00170-008-1641-z

[41] Natarajan, U. Saravanan, R. Periasamy, V.M. Application of particle swarm optimization in artificial neural network for the prediction of tool life. International Journal of Advanced Manufacturing Technology. 2007; (31): 871-876. $\mathrm{http} / / \mathrm{dx}$.doi10.1007/s00170-005-0252-1

[42] Noor, M. M., Kadirgama,K. Rahman, M. M. Particle swarm optimisation prediction model for surface roughness. International Journal of the Physical Sciences. 2011; 6(13): 3082 -3090. http//dx.doi.org/10.5897/IJPS10.263 